\title{
Control of 3-Axis Satellite Reaction Wheel using PID Control Optimized Genetic Algorithms
}

\author{
Erna Kusuma Wati, Yulio Ramadhan, Hari Hadi S
}

\begin{abstract}
Satellite Attitude Determination and Control System (ADCS) uses an active actuator with a Reaction wheel. This study uses PID and genetic algorithms to control the Reaction wheel. The initial population was 200 , and the crossover rate was 0.8 , the mutation constant was 0.01 with a stop generation criteria of 50 generations. Reaction Wheel Control in a closed ring with optimized PID control The Genetic Algorithm has transient response characteristics that are 1 seconds rise time, 9 seconds set time, $33.2 \%$ overshoot with an ITAE performance index of 481,9479. Use the Matlab program to conduct a Smart Nanosatellite Attitude Propagator (SNAP) simulator to create a 3-axis reaction wheel model as its actuator. The satellite is the object of control, simulating the satellite conditions in a tumbling state having the initial angular velocity $[0.50 .50 .5]^{\circ} /$ second then stumbling which makes the satellite angular velocity to $\left[\begin{array}{lll}0 & 0 & 0\end{array}\right]^{\circ} /$ second. Roll and yaw axes have a significant enough error that is1 $\mathrm{rad} / \mathrm{s}$ and $\mathbf{- 1} \mathrm{rad} / \mathrm{s}$ while the pitch axis has a small error that is $1.5 \times 10-3 \mathrm{rad} / \mathrm{s}$ and $-1.5 \times 10-3 \mathrm{rad} / \mathrm{s}$.
\end{abstract}

Keywords : Reaction Wheel, Genetic Algoritm, Satellite.

\section{INTRODUCTION}

$A_{t+1}$ Attitude Determination Control System (ADCS) is one of the satellite subsystems, whose task is to determine and control the orientation of satellites [2]. Control of satellite orientation is crucial to run well. Figure 1 is a block diagram of the ADCS component, which includes input, controller, actuator, measurement, and output

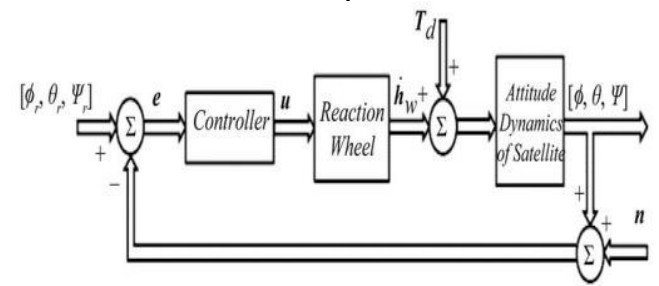

Fig 1. ADCS Diagram Blok

To model satellite dynamic equations using Simulink and MATLAB software [3].

Revised Manuscript Received on February 05, 2020.

* Correspondence Author

Erna Kusuma Wati*, Physics of Engineering , Universitas Nasional, Jakarta, Indonesia. Email: ernakusuma.w@gmail.com

Yulio Ramadhan, Physics of Engineering, Universitas Nasional, Jakarta, Indonesia

Hari Hadi S, Physics of Engineering , Universitas Nasional, Jakarta, Indonesia

(C) The Authors. Published by Blue Eyes Intelligence Engineering and Sciences Publication (BEIESP). This is an open access article under the CC BY-NC-ND license (http://creativecommons.org/licenses/by-nc-nd/4.0/)
The control system in this study is PID and combines Sliding mode with PID (Sliding-PID) to get more optimal control. Another control is to use artificial neural networks (ANN). ANN get optimal control on the controller, then when simulating it must be with a small satellite that has three reaction wheels. in this Research will design a reaction wheel using PID control and optimization with Genetic Algorithms using a MATLAB-based Smart Nano satellite Attitude Propagator (SNAP) simulator.

PID is a control system consisting of three types, namely the $\mathrm{P}$ (Proportional) control, which functions to accelerate the response, I control (Integral), which functions to correct and reduce offset, and control D (Derivative) which functions to predict and reduce overshoot. P (Proportional) control, PI (Proportional-Integral) control, PD (Proportional-Derivative) control, and PID (Proportional-Integral-Derivative) control [4].

PID control mathematically as follows

$$
M(t)=\operatorname{Kp}\left[e(t)+1 / T i \int e(t) d t+T d(d e(t) /) d t\right]
$$

Genetic Algorithms are heuristic search algorithms based on biological evolutionary mechanisms. The diversity of natural evolution is a variation of chromosomes between individual organisms. These chromosome variations will affect the rate of reproduction and the level of the organism's ability to stay alive. John Holland said that every problem in the form of adaptation (natural or artificial) could be solved by formulation in genetic terminology [5]

LAPAN-TUBS AT is a microsatellite developed by the National Institute of Aviation and Space (LAPAN) in collaboration with the Technical University of Berlin (Technische UniversitÂat Berlin; TU Berlin). This vehicle is designed based on another satellite called DLR-TUBS AT but also includes a new star sensor. The box-shaped LAPAN-TUBS AT satellite weighing 57 kilograms and dimensions $45 \times 45 \times 27$ centimeters to directly monitor the situation on Earth such as forest fires, volcanoes, floods, store and forward communication messages in Indonesian territory, and for mobile communication missions

Reaction Wheel (RW) is an active actuator to regulate satellite rotation. RW works based on the principle of conservation of angular momentum; changes in the rotational speed of RW eat torque that will affect the rotational motion of the satellite. RW actuators consist of several parts, namely the Brushless DC Motor (BLDC) as a torque generator on the Flywheel transfer function as follows. 


\section{METHOD}

\section{A. Modeling wheel Reaction Control System}

Reaction Wheel (RW) is an active actuator to regulate satellite rotation. RW works based on the principle of conservation of angular momentum; changes in the rotational speed of RW eat torque that will affect the rotational motion of the satellite. RW actuators consist of several parts, namely the Brushless DC Motor (BLDC) as a torque generator on the Flywheel. Transfer function as follows:

$$
\begin{aligned}
& L_{a} \frac{d I_{m}}{d t}=V-I_{a} R_{a}-K_{b} W_{W} \\
& l \frac{d W_{u n}}{d t}=K_{t} i_{\alpha}-B W_{m}
\end{aligned}
$$

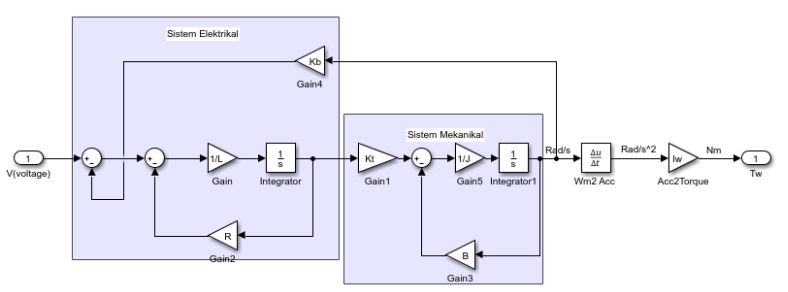

Fig 2. Diagram Block Reaction wheel

Table 1. BLDC (2444 048B) and Flywheel Motor

\begin{tabular}{|c|c|}
\multicolumn{2}{c}{ Spesicfication[15] } \\
\hline Resistor (R) & $8.4 \mathrm{Ohm}$ \\
\hline $\begin{array}{c}\text { constanta } \\
\text { Back-EMF (Ke) }\end{array}$ & $2.115 \times 10^{-3} \mathrm{~V} / \mathrm{RPM}$ \\
\hline Constanta Torsi (J) & $20.2 \times 10^{-3} \mathrm{Nm} / \mathrm{A}$ \\
\hline $\begin{array}{c}\text { Inersia Rotor } \\
\text { (Irotor) }\end{array}$ & $6.5 \mathrm{~g} \cdot \mathrm{cm}^{2}$ \\
\hline Mass Flywheel & $652 \mathrm{~g}$ \\
\hline Inersia Flywheel & $912.6 \times 10^{-6} \mathrm{~kg} \cdot \mathrm{m}^{2}$ \\
\hline
\end{tabular}

To make an open ring wheel reaction system test, it requires data specifications Table 1 to insert it into a block diagram. step input signal with initial value $=0$ and final value $=1$. The input data step gets information about the stability of the system because it has a constant final value. The results in Figure 3 show the reaction wheel response curve exceeds the desired setpoint (final value), so it requires control so that the system can reach the setpoint. The reaction wheel response in the opening ring has a rise time of 424 seconds and a settling time of 755 seconds, where the final value obtained is 1.32 .

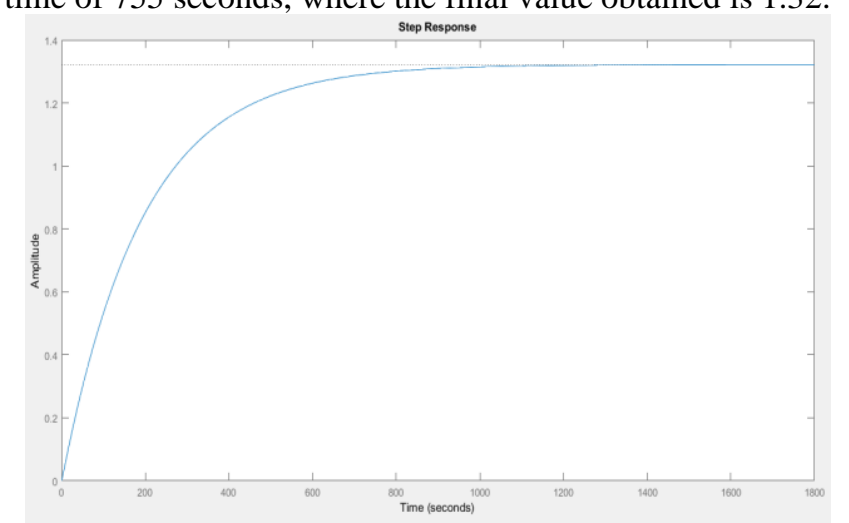

Fig 3. Reaction Wheel Response to open ring

\section{B. Reaction Wheel Control}

Figure 4 is a closed ring wheel reaction control system with error is the angular velocity value of the reaction wheel to obtain the angular velocity $\mathrm{W} \_$des $=$W_ref-W_m

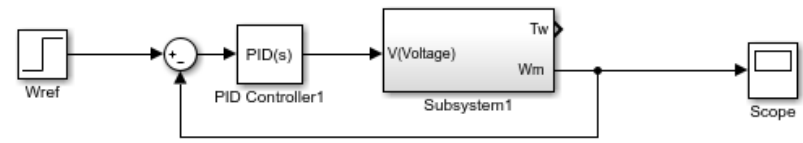

Fig 4. Closed ring wheel Reaction Control System

\section{The Ziegler-Nichols Open Circle Penalty}

Penalty aims to obtain PID control parameters. The method in this study is the Z-N tuning method in the open ring. The s-shaped curve has two constants, namely dead time (L) and delay time $(\mathrm{T})$. the next step is to calculate the constant based on Table 2. Thus obtaining an s-shaped curve response. Then got the following parameters

a. Dead time (L) Paramater

$0.6 * \Delta \mathrm{PV}=0.63 * 1.32=0.83 \rightarrow t_{63 \% 6}=292.76-108=184.76 \mathrm{~s}$

b. Delay Time (T) Parameter

$\mathrm{T}=100-108=8 \mathrm{~s}$

Table 2. Z-N Tuning Open Circumference

\begin{tabular}{|c|c|c|c|}
\hline $\begin{array}{c}\text { Tipe } \\
\text { PID }\end{array}$ & $\mathrm{Kp}$ & $\mathrm{Ki}$ & $\mathrm{Kd}$ \\
\hline $\mathrm{P}$ & $\frac{T}{L}$ & $\infty$ & - \\
\hline PI & $0.9 \frac{T}{L}$ & $\frac{L}{0.3}$ & - \\
\hline PID & $1.2 \frac{T}{L}$ & $2 \mathrm{~L}$ & $0.5 \mathrm{~L}$ \\
\hline
\end{tabular}

\section{Optimization of Genetic Algorithms}

Determine PID control parameters using genetic algorithms. The parameters in the tuning of the PID control (randomly) are in the table 3 .

Table 3. Genetic Algorithm Parameters

\begin{tabular}{|c|c|}
\hline Initial population & 200 \\
\hline Crossover rate & 0.8 \\
\hline Mutation Constant & 0.01 \\
\hline Elitism & 10 \\
\hline Termination Criteria & 50 Generation \\
\hline
\end{tabular}

Satellite Dynamics Diagram Block 


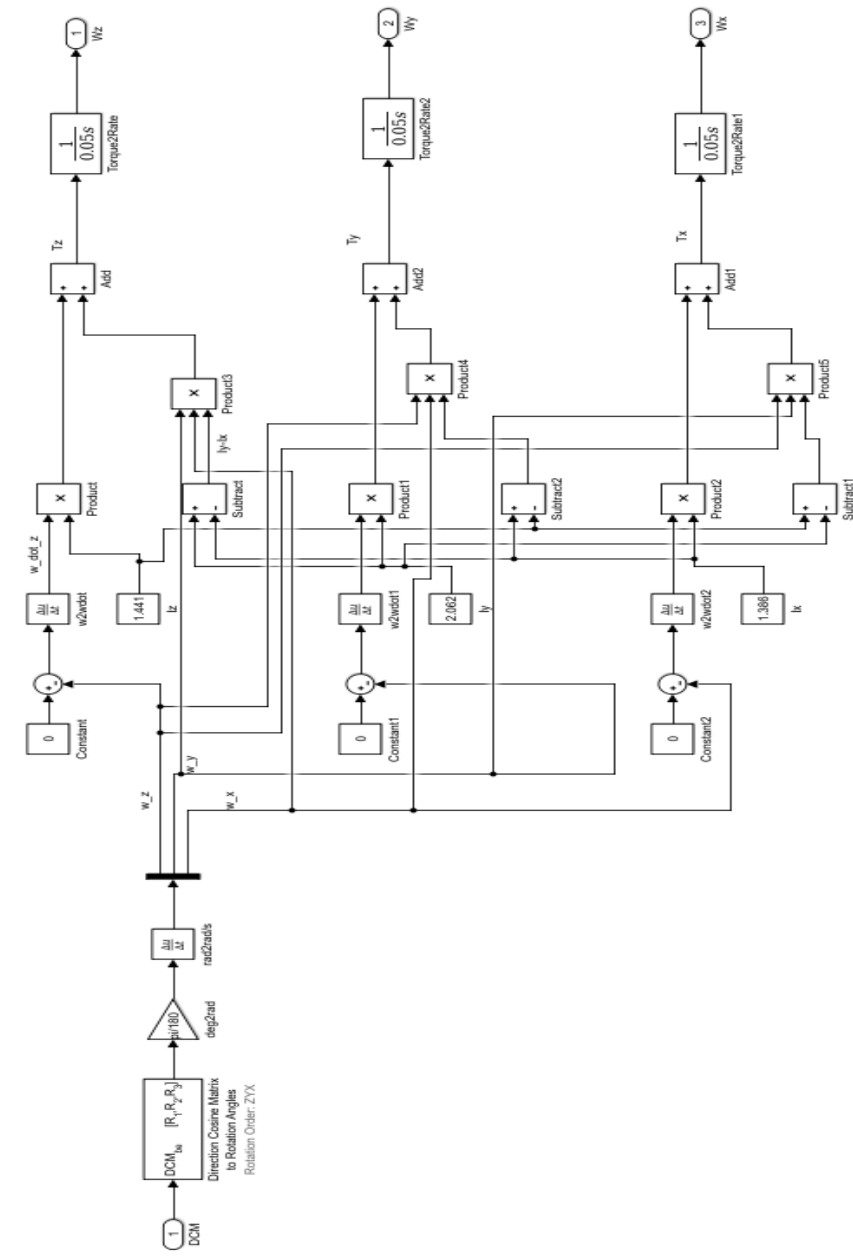

Fig 5. Satellite Dynamics Diagram Block

\section{E. Simulator}

To carry out satellite orientation simulation in this study using the MATLAB program with the Smart Nanosatellite Attitude Propagator (SNAP) platform. SNAP is a 6-DOF satellite orientation propagator implemented in MATLAB. As shown in Figure 6, there are several parts, namely Orbital Information, Satellite Description, and Simulation Parameters.

a. Orbital information ; in this section, the input parameters are the orbit information from the satellite.

b. Satellite Description UTo ; enter information related to satellite specifications.

c. Simulation Parameters; Contains parameters in the simulation, such as the duration of the simulation and the initial rotation (tumbling)

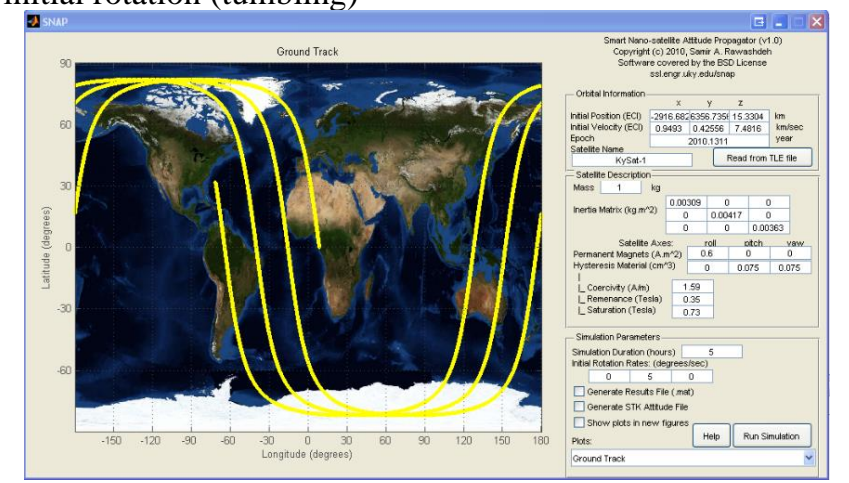

Fig 6. SNAP interface

\section{RESULT AND DISCUSSION}

Closed-loop wheel reaction control system with an error signal is the angular velocity value of the reaction wheel so that the angular velocity is W_des = W_ref-W_m.

PID control requires $\mathrm{P}, \mathrm{I}$, and $\mathrm{D}$ as its control parameters, tuning to get optimal $\mathrm{P}, \mathrm{I}$, and $\mathrm{D}$ parameters. There are many tuning methods, including Cohen-Coon, Ziegler-Nichols.

Table 4. PID parameters with Z-N tuning

\begin{tabular}{|c|c|}
\hline PID Parameter & Value \\
\hline Proporsional & 27.714 \\
\hline Integral & 16 \\
\hline Derivatif & 4 \\
\hline
\end{tabular}

Although the initial value generation process is random, the reference value is still around the amount of the tuning that has been done. The lower limit is [-30 -30 -30], and the upper limit is [30 30 30]. The process of PID Optimization by Genetic Algorithm for ten times.

PID control parameters use genetic algorithms. PID Tuning using Genetic Algorithms with parameters according to table 5, you will get the parameters P, I, D, as in table 3 .

\begin{tabular}{|c|c|}
\hline Parameter PID & Nilai \\
\hline Proporsional & 9.983 \\
\hline Integral & 0.938 \\
\hline Derivatif & -9.99 \\
\hline ITSE & 481.9479 \\
\hline
\end{tabular}

The optimization results show that the highest ITAE value is 1134.44, and the lowest value is 481.9479. The second transient optimization response for the input step is as shown in Figure 7

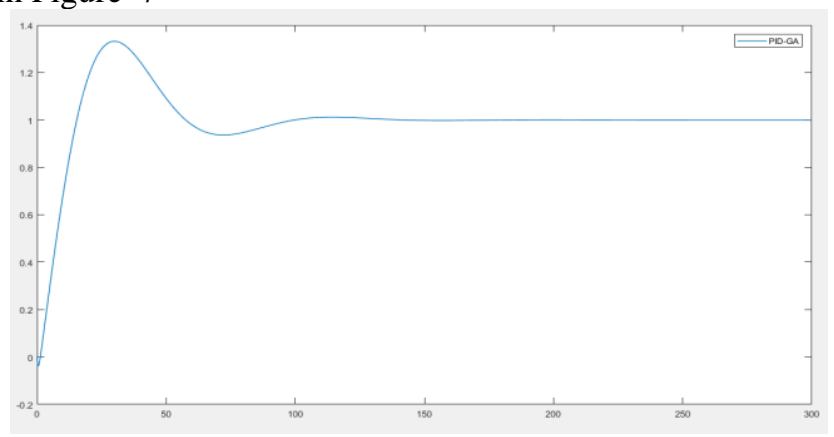

Fig 7. Transient response to step input

Based on this response, the reaction wheel reaches a setpoint of $1 \mathrm{rad} / \mathrm{s}$ less than 200 seconds. The transient response characteristics in table 5

Table 5 Characteristics of PID-GA Transient Responses.

\begin{tabular}{|c|c|}
\hline Karakteristik & Value \\
\hline Rise time & $11 \mathrm{sec}$ \\
\hline Settling time & $91 \mathrm{sec}$ \\
\hline Overshoot & $33.2 \%$ \\
\hline
\end{tabular}

\section{F. 3-Axis Reaction Wheel Control}

In this simulation, using three wheels of reaction for each of the $\mathrm{x}, \mathrm{y}, \mathrm{z}$ axes, and each reaction wheel are identical so that the optimization value of PID on the three reaction wheels is the same. 
Then the block diagram is shown in Figure 8 with the output in the form of torque for each axis that will be input in satellite control, with an error value in the way of angular velocity resulting from the reaction wheel.

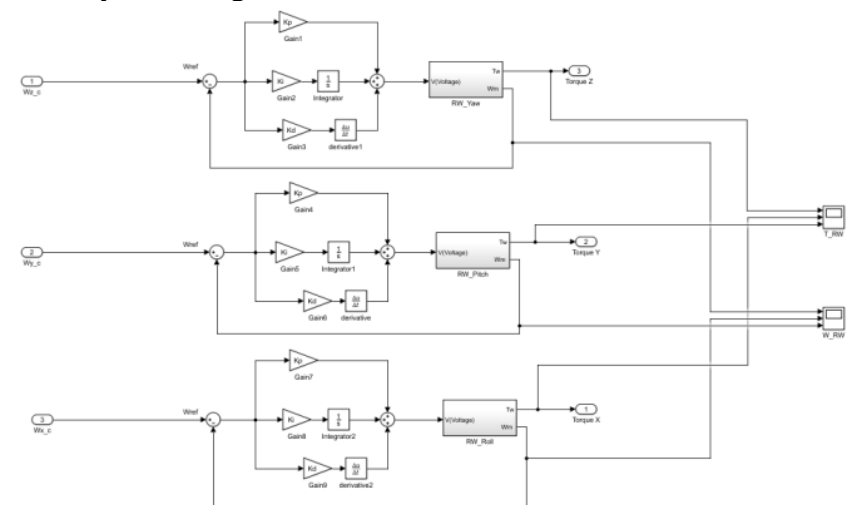

Fig 8. 3-Axis Reaction Wheel Diagram Block

By using the SNAP simulator for 4 hours is one satellite orbit rotation LAPAN TUBS AT A1. By making the satellite in a tumbling state (the satellite has the initial angular velocity $\left[\begin{array}{lll}0,5 & 0,5 & 0,5\end{array}\right]^{\circ /} / \mathrm{sec}$. , the next step is detumbling, which is making the satellite angular velocity to $\left[\begin{array}{lll}0 & 0 & 0\end{array}\right]^{0 /} / \mathrm{sec}$. Values less than 0 or minus (-) indicate movement in the opposite direction from values greater than 0 or plus $(+)$. From figure $4.7 \mathrm{~d}$ at 50 and 100 minutes, the satellite has increased angular velocity. On the roll axis, the greatest angular velocity value is $19.65^{\circ} / \mathrm{sec}$ in minute 85 . The pitch axis has the largest angular velocity value of $3.33^{\circ}$ / sec at 86 minutes. And the yaw axis has the largest angular velocity value of $13.56^{\circ} /$ seconds at minute 85 . Then all axes experience a slowing of the angular velocity. The value of satellite angular velocity at the end of the simulation is $\left[\begin{array}{lll}-0,3 & 0 & 1,2\end{array}\right]^{\circ} /$ sec.

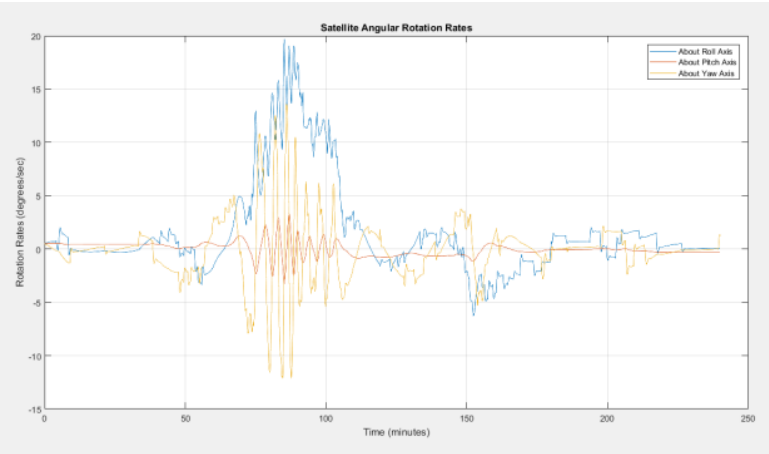

Fig 9. Satellite Angular Velocity

In Figure. The angular speed of the reaction wheel is blue, and Green is the desired angular velocity or setpoint. Figure 10 shows that the response speed of the reaction wheel angle follows the setpoint. Then Figure 11 shows the reaction wheel torque in the range of $0.015 \mathrm{Nm}$ and $-0.015 \mathrm{Nm}$, which can affect satellites on the roll axis

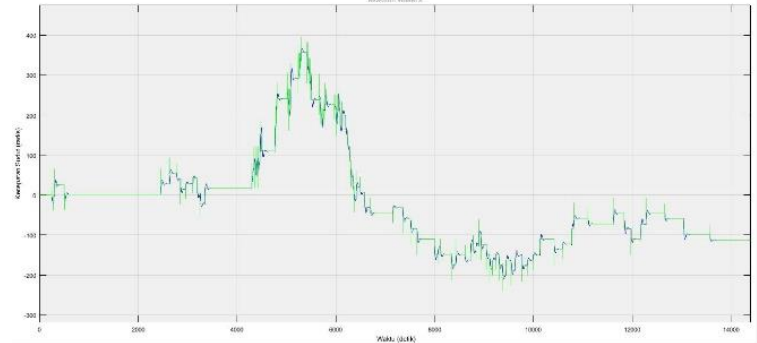

Fig 10. Angular velocity Reaction Wheel X-Axis

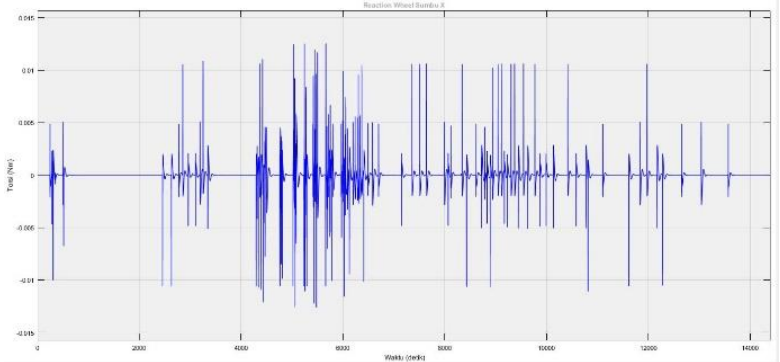

Fig 11. Torsi Reaction Wheel X-Axis

Next in Figure 12 and 13 shows a graph for angular velocity and torque by the reaction wheel on the $\mathrm{Y}$-axis. The angular velocity in Figure 12 is a red line, and the desired angular velocity is green. Figure 13 shows the torque for the reaction wheel on the $\mathrm{Y}$-axis with a torque range between $0.0001 \mathrm{Nm}$ to $-0.0001 \mathrm{Nm}$.

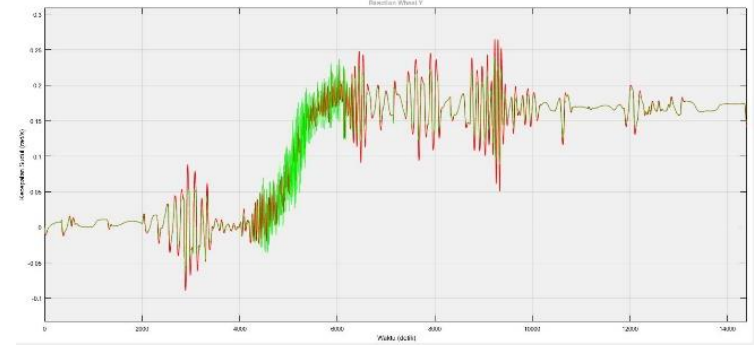

Fig 12. Angular velocity Reaction Wheel Y-Axis

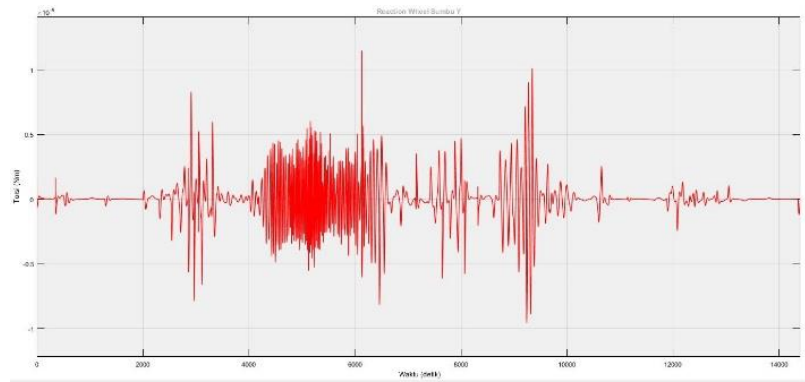

Fig 13. Torsi Reaction Wheel Y-Axis

Then Figure 14 is a graph of angular velocity and torque on the Z-axis reaction wheel. The angular velocity shown in Figure 14 is a yellow line, and the setpoint angle is green. Figure 15 shows the torque in the reaction wheel on the Y-axis with a torque range between $0.015 \mathrm{Nm}$ to $-0.015 \mathrm{Nm}$.

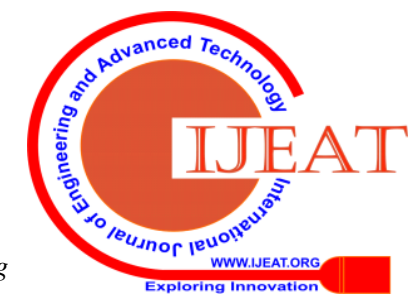




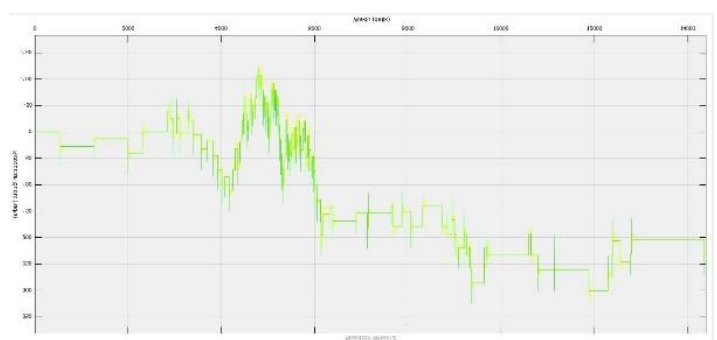

Fig 14. Angular velocity Reaction Wheel Z-Axis

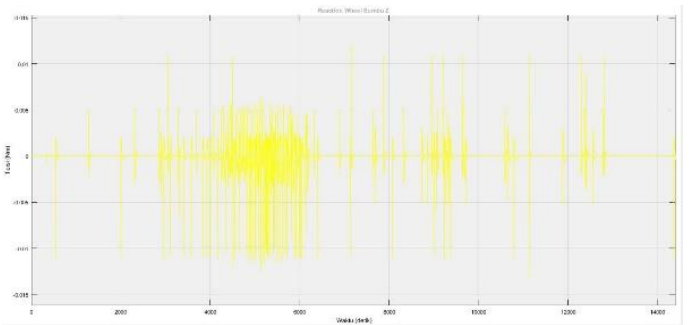

Fig 15. Torsi Reaction Wheel Z-Axis

The average value of the error in the closed wheel of the reaction wheel for each $\mathrm{x}, \mathrm{y}$, and the $\mathrm{z}$-axis in table 4.4. The error value in the closed wheel of the reaction wheel is the value of the angular velocity produced by the reaction wheel reduced by the desired angular velocity value $\mathrm{W} \_$error $=$ W_ref-W_m

Table. $6 W_{\text {error }}$ Average

\begin{tabular}{|c|c|}
\hline $\begin{array}{c}\text { Reaction } \\
\text { Wheel }\end{array}$ & Average Error \\
\hline $\mathrm{X}$ & $-0,0064 \mathrm{rad} / \mathrm{s}$ \\
\hline $\mathrm{Y}$ & $1,909 \times 10^{-6} \mathrm{rad} / \mathrm{s}$ \\
\hline $\mathrm{Z}$ & $0,0134 \mathrm{rad} / \mathrm{s}$ \\
\hline
\end{tabular}

If you see the angular velocity response generated by the 3 -axis reaction wheel is good enough because the Angular velocity value matches the setpoint value. Looking at table 6, the average $\mathbf{W}$ _error during the simulation for each angle has a value below $1 \mathrm{rad} / \mathrm{s}$, and this means that the results of this response are under the response wheel's closed ring response.

\section{CONCLUSION}

1. Genetic Algorithm uses an initial population of 200 populations, a crossover rate of 0.8 , a mutation constant of 0 . 01. The stopping criterion is 50 generations with a fitness function based on the PID performance index, namely ITAE, by optimizing ten (10) times. produces P, I, and $\mathrm{D}$ values with the lowest ITAE performance index of 481,9479 for a reaction wheel, namely Proportional (P) 9,983, Integral (I) 0.938, and Derivatives (D) -9.99

2. Reaction Wheel in its closed circumference using the optimized PID control Genetic Algorithm has transient response characteristics that are 11 seconds rise time, 91 seconds set time, 33.2\% overshoot. One reaction wheel becomes three identical pieces in the framework of controlling 3-axis

3. Control of the LAPAN-TUBS AT A1 3-Axis Reaction Wheel using the SNAP Simulator. By entering the orbital parameters and the LAPAN-TUBS AT A1 satellite body, in a tumbling state, it has the initial angular velocity [0.5 $0.50 .5]^{\circ} / \mathrm{sec}$ then detumbling by making the satellite angular velocity to $\left[\begin{array}{lll}0 & 0 & 0\end{array}\right]^{\circ} / \mathrm{sec}$. On the roll axis, the greatest angular velocity value is $19.65^{\circ} / \mathrm{sec}$ in 85 minutes. The pitch axis has the largest angular velocity value of $3.33^{\circ} / \mathrm{sec}$ in 86 minutes. And the yaw axis has the largest angular velocity value of $13.56^{\circ} /$ seconds in 85 minutes. Then all axes experience a slowing down of angular velocity. The value of satellite angular velocity at the end of the simulation is [ $(-0.3 \& 0 \& 1.2)]^{\circ} / \mathrm{sec}$

4. Based on the 3-axis reaction wheel response graph, the PID control optimized by the genetic algorithm gets a pretty good value because the angular velocity value matches the setpoint value with the average W_error for all angles having values below $1 \mathrm{rad} / \mathrm{s}$.

\section{REFERENCES}

1. S. R. Starin, Attitude Determination and Control Systems, Microcosm, 2010.

2. N. Imroatul and H. Nurhadi, "Komparasi Sistem Kontrol Satelit (ADCS) dengan Metode Kontrol PID dan Sliding-PID," Jurnal Teknik POMITS, vol. I, no. 1, 2012.

3. S. Li, J. Yuan, J. Luo and W. Ma, "Satellite Attitude Control through Evolving a Neural Network," in International Conference on Mechatronics and Automation, Xi'an, 2010.

4. "What Is an Orbit?," National Aeronautics and Space Administration, 7 July 2010.2 [Online]. Available: https://www.nasa.gov/audience/forstudents/5-8/features/nasaknows/w hat-is-orbit-58.html. [Accessed 6 March 2018].

5. Types of Orbits," European Space Agency, 17 April 2017. [Online]. Available:

https://www.esa.int/Our_Activities/Space_Transportation/Typ es_of_orbits. [Accessed 6 March 2018].

6. H. Riebeek, "Catalog of Earth Satellite Orbits," Earth Observatory, National Aeronautics and Space Administration, 4 September 2009. [Online]. Available: https://earthobservatory.nasa.gov/Features/OrbitsCatalog/. [Accessed 6 March 2018].

7. R. Mohsenipour, H. Nemati and dkk, "Attitude Control of a Flexible Satellite by Using Robust Control Design Methods," Intelligent Control and Automation, vol. 4, no. 3, 2013.

8. R. E. Kalman, A New Approach to Linear Filtering and Prediction Problems, Baltimore: Research Institute for Advance Study, 1960.

9. K. J. Astrom and T. Hugglund, PID Controllers: Theory, Design, and Tuning, Instrument Society of America, 1995.

10. E. Stella Ogochukwu, A. Desmond Okechukwu, and O. Godfrey Nnaegbo, "Construction And Testing Of Ultrasonic Bird Repeller," J. Nat. Sci. Res. www.Online), vol. 2, no. 9, pp. 2225-921, 2012.

11. Atmega168," pp. 121-134, 2012.

12. S. Trajectory, P. Dan, F. Pada, and R. Obstacle, "Journal of Control and

13. Tatsuro Baba, "Time-Frequency Analysis Using Short Time Fourier Transform," Open Acoust. J., vol. 5, pp. 32-38, 2012.

14. A. G. De Oliveira et al., "Bird acoustic activity detection based on morphological filtering of the spectrogram," Appl. Acoust., vol. 98, pp. 34-42, 2015.

\section{AUTHORS PROFILE}

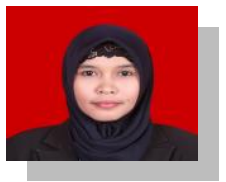

Kusuma W obtained her S.Pd,Si from the Yogyakarta National University College of Physics Education, Yogyakarta, Indonesia. Her completed his M.Sc in Physics in 2013 at the Gadjah Mada University. Currently, she is a Assistant Profesor Universitas Nasional, Jakarta, Indonesia

Yulio Ramadhan, Bachelor of Engineering Physics, Universitas Nasional, Jakarta, Indonesia

Hari Hadi S, Associate Profesor of Engineering Physics, Universitas Nasional, Jakarta, Indonesia

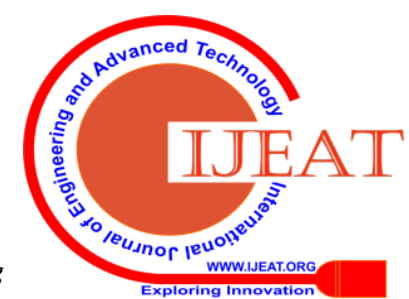

